Instructions for authors, subscriptions and further details:

http://brac.hipatiapress.com

\title{
Pensar el Dibujo: el Acontecimiento del Verbo Dibujar y el Debate en Torno a su Evaluación.
}

José Ignacio León Luque ${ }^{1}$

1) Escuela de Arte, Facultad de Artes. Pontificia Universidad Católica de Chile.

Date of publication: October $3^{\text {rd }}, 2021$

Edition period: October 2021 - February 2022

To cite this article: León, J. I. (2021). Pensar el Dibujo: el Acontecimiento del Verbo Dibujar y el Debate en Torno a su Evaluación. Barcelona, Research, Art, Creation, 9(3), 294-324. doi: 10.17583/brac.6407

To link this article: https://doi.org/10.17583/brac.6407

PLEASE SCROLL DOWN FOR ARTICLE

The terms and conditions of use are related to the Open Journal System and to Creative Commons Attribution License (CC-BY). 
BRAC - Barcelona Research Art Creation. Vol. 9 No. 3, October 2021, pp. 294-324

\section{Pondering Drawing: the Event of the Verb Draw and the Debate Surrounding its Evaluation}

José Ignacio León Luque

Facultad de Artes. Pontificia Universidad Católica de Chile.

(Received: 16 October 2020; Accepted: 17 March 2021; Published: 3 October 2021)

\section{Abstract}

In this text we ask ourselves about what the action of drawing requires as an event itself, to then propose functional and procedural drawing possibilities that will be linked to elements related to Research and Creation in Art projects. This decision comes from a series of questions about the difference perspectives that operate between the experience of creation and the limits to which it is bound in the face of external conditions that submit its process to rigid and measurable terms, such as in the application process of a project for its financing, considering it essential to expand the production frontier, making both the procedure and functionality a field of test and investigation whose result is, consequently, open to what the creation experience itself offers, where not everything is possible to be submitted to objective criteria, as in the case of drawing.

At the end of this text, examples of in situ registration are presented for a journey through drawing, where the positions taken by the draftsman regarding the motif and the way in which he constructs and communicates the information based on the unscheduled findings that the action of drawing requires.

Keywords: Drawing, technique; functionality, event, evaluation criteria 
BRAC - Barcelona Research Art Creation. Vol. 9 No. 3, October 2021, pp. 294-324

\section{Pensar el Dibujo: el Acontecimiento del Verbo Dibujar y el Debate en Torno a su Evaluación}

José Ignacio León Luque

Facultad de Artes. Pontificia Universidad Católica de Chile.

(Recibido: 16 octubre 2020; Aceptado: 17 marzo 2021; Publicado: 3 octubre 2021)

\section{Resumen}

En el presente texto nos preguntamos acerca de lo que requiere la acción de dibujar como acontecimiento en sí mismo, para luego plantear posibilidades funcionales y procedimentales del dibujo que se vincularán con elementos relativos a proyectos de Investigación y Creación en Arte.

Esta decisión obedece a una serie de cuestionamientos sobre las distintas perspectivas que operan entre la experiencia de la creación y los límites a que se obliga frente a condicionantes externos que someten su proceso a formatos rígidos y mensurables, como es el caso de los requisitos para optar a fondos de financiamiento -entre otros escenarios similares de evaluación- al considerar esencial expandir la frontera de la producción, haciendo tanto del proceso como de la funcionalidad un campo de prueba cuyo resultado quede, en consecuencia, abierto a las características del acontecimiento de la creación, donde no todo es posible de someter a criterios objetivos, como ocurre en el caso del dibujo.

Al final de este texto se presentan ejemplos de registro mediante dibujo in situ, en donde se cuestionan las posiciones que adopta el dibujante respecto del motivo y la forma en que construye y comunica la información tras los hallazgos no programados que requiere la acción de dibujar.

Palabras clave: Dibujo, técnica, funcionalidad, acontecimiento, criterios de evaluación 


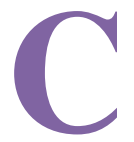

uando nos preguntamos sobre el conocimiento que involucra el acto de dibujar o los alcances de la experiencia de quien lo contempla, es decir la forma en que se infiere lo que el dibujante sabe o no, ¿a qué nos referimos y en qué se basa ese juicio? En otras palabras, ¿qué debe saber el o la dibujante para hacer y expresar por medio del dibujo un producto que calificamos como consistente y portador de significado dentro de un contexto cultural? ¿Cuál es ese criterio para valorar aquello que obedece a la acción de dibujar y su resultado, el dibujo?

Mucha de la literatura que trata este tema, centra el saber en el dominio técnico. Pero al poner atención en las preguntas que fundamentan la funcionalidad y procedimiento del dibujo, ¿cómo se podría ponderar la técnica? ¿Qué es ser un buen dibujante? ¿Se consideraría el "saber hacer" como el dominio de ciertos esquemas técnicos previos a la acción de dibujar y que siempre se aplican de forma similar, independiente de la realidad que se intenta comprender a través del dibujo? Si la técnica es algo que se adquiere en la práctica, ¿qué motivará la práctica? ¿La sola voluntad de hacer un buen trabajo? (Sennett, 2009).

A partir de Heidegger, comprendemos la técnica como causante y medio para un logro, y este enfoque nos permite plantear que lo técnico no está antes de la búsqueda o la motivación, sino que se descubre justamente con ésta para transformarla en obra propuesta (Heidegger, 1997). Ello equivale a decir que la técnica surge en el proceso y se renueva en éste. De otro modo, es posible sostener que se trataría de un modelo a repetir para un resultado esperable. Sin duda, es posible asociar lo técnico con el concepto de estrategia si se tiene claridad sobre la forma en que se proyecta el resultado, y quizá eso sería lo que se entiende por saber hacer. Pero ¿qué sucede si antes del suceso no se tiene certeza sobre cómo alcanzar un logro o el sentido de éste? Cuando estas variables se proyectan con un desenlace abierto, como si se tratase de un salto al vacío, fuera de la zona de confort, su fin es descubrir o develar (Heidegger, 1997).

Al considerar la práctica artística como investigación, el profesor Henk Borgdorff nos invita a buscar esta identidad y diferencia en la indagación 
acerca de la naturaleza del objeto a investigar, a través del conocimiento que produce y gracias a los métodos de trabajo (Borgdorff, 2006).

En el contexto de lo señalado, este artículo propone una posibilidad de abordar estas materias a partir del análisis de los constituyentes con que se trabaja en Investigación, tomando como punto de partida la experiencia creativa en el acto del dibujar y sus necesidades objetivas de materialización.

Quienes trabajamos con medios plásticos, al momento de postular a fondos para creación (hoy Investigación-Creación), debemos adaptar nuestro hacer al formato Proyecto, en la lógica de la investigación científica que requiere claridad sobre aspectos mínimos para comunicación de un problema. En sus ejes básicos, se pide exponer sobre el qué o la temática, asunto o preguntas que motivan el hacer (Problema o Pregunta de Investigación); el para qué, la funcionalidad y objetivos; el cómo, los aspectos técnicos o procedimentales (Metodología, incluidas las hipótesis de trabajo); el logro, la propuesta u obra (Metas) y, en la actualidad, el impacto del proyecto, asunto directamente ligado a aspectos de productividad y mercado.

"El artista realiza su pensamiento en los medios cualitativos mismos con que trabaja, y sus fines se encuentran tan cerca del objeto que produce que se funden directamente en él" (Dewey, 2008, p. 17). En el mismo párrafo, el autor nos dice que el artista, al igual que el científico, tiene cuestionamientos asociados a su trabajo, en cuyo caso "el pensamiento está más inmediatamente incorporado al objeto".

Nos situamos en la Investigación-Creación del hacer/pensar, de la práctica, en donde lo técnico tiene por función desvelar la propuesta. Así, al situarse frente a las preguntas sobre las cuales no hay aún procedimientos ciertos, ¿qué lugar ocupa el intento de descubrir y develar una motivación incierta, el impulso movido por la intuición? ¿Cómo hemos de alcanzar la comunicación en un formato al cual forzadamente nos hemos debido adaptar y en un terreno en donde la Academia ha decidido sin mediación alguna conjugar los parámetros de las ciencias puras con los de la Creación e Investigación en Arte, llevándola, en consecuencia, a un lugar que no le es natural?

Resulta innegable que las preguntas de investigación pueden adaptarse al formato de Investigación Proyectual para la Creación, teniendo en consideración que el hacer/pensar creativo tiene un particular procedimiento que obedece a determinaciones sobre lo cual solo cabe adelantar posibles, ya que su expresión/comunicación deviene del proceso que los provoca. Entonces, si nos concentramos en el proceso específico del dibujo, su acción y su práctica, ¿cómo expresar algo que no ha ocurrido sino hasta cuando sucede? 
A partir de estas consideraciones, pondremos el acento en las preguntas que para la creación artística y específicamente la acción de dibujar, se entrelazan, colaboran y co-participan (Heidegger, 1997) en el qué, el para qué y el cómo. Aunque no es lo que intentaremos responder, abordar el eje de este texto implica preguntarse cómo la Academia acoge hoy el cúmulo de reflexiones creativas que suponen las dinámicas proyectuales de las obras en proceso, cómo evalúa $\boldsymbol{e l}$ logro obtenido con las prácticas artísticas y cuál es $\boldsymbol{e l}$ impacto del ejercicio reflexivo del arte y de las obras en exhibición y, en este caso, lo referido a la tríada Investigación-Creación-Dibujo.

\section{Funcionalidad y Técnica, el Universo entre los Conceptos}

Si la motivación para dibujar se sitúa en el aspecto funcional, en el para qué, probablemente el verbo configuraría un conjunto de posibles relacionados con una serie de conceptos que escalan en complejidad cualitativa:

\begin{tabular}{|l|l|}
\hline Preparación & Acción \\
\hline Pensar & Estudiar \\
Proponer & Reconocer \\
Proyectar & Traducir \\
& Interpretar \\
& Representar \\
& Expresar \\
& Comunicar \\
\hline Analizar & Observar \\
Comprender & Experimentar \\
Sintetizar & Anotar \\
& /Documentar \\
& Describir \\
& Narrar \\
& Valorar \\
\hline
\end{tabular}

Se trata de conceptos que involucran el saber intencionado que postulamos se descubrirá a través de la práctica y como resultado de ésta, no antes ni como aspectos subalternos a un saber anterior. Siendo así, el verbo y sus combinaciones requerirían uno o más de estos procedimientos cuando la acción de dibujar tiene por fin representar, comprender y comprenderse. 
Esta propuesta responde a la lógica de que una acción compleja exige un plan previo, pero ¿y si a partir del procedimiento y su suceso descubriéramos cuáles son las posibilidades para alcanzar los requerimientos y solicitaciones funcionales, invirtiendo el "orden lógico"? Si las políticas de fomento a la creación artística responden a un enfoque de productividad, la experiencia creativa indica que otro enfoque coherente con el arte es considerar que parte de "la productividad" surge de la acción de crear y la experiencia del dibujo parece ratificarlo.

Fruto de reflexiones sobre el trabajo de dibujantes contemporáneos y propios, a lo largo de mi trayectoria docente he propiciado en los estudiantes una suerte de desmantelamiento del dibujo en fases como proceso, funciones y aspectos implicados, que más adelante se indicarán entre paréntesis. Planteamos que en arte, un proyecto puede ser concebido como una acción hacia el descubrimiento, en lugar de un plan cuyo hallazgo esté determinado por un objetivo general o específico. De acuerdo con ello, es posible afirmar que en la experiencia del dibujo se ponen a prueba la distancia, el movimiento y/o posición corporal de trabajo respecto al soporte, así como también su tamaño, forma y superficie (Cuerpo y soporte). Qué tal dibujar en un lugar diferente del habitual o descontextualizar la experiencia y las condiciones ambientales, dibujando en el tren subterráneo, un cine, supermercado o centro comercial, exponiéndose al desafío en condiciones distintas a las del taller (Dibujar/desplazamientos). Qué tal mover, rotar, cambiar, distanciar el punto de vista respecto de un algo allá fuera para representar, comprender y de esta forma comprenderse (Corporalidad, punto de vista y espacio). Quizá, dibujar en torno a las sensaciones táctiles o auditivas, obstaculizando o prescindiendo de la visión (Sujeto percipiente y dibujo). Atender a la cinestesia respecto de la representación en y del espacio que forma la tríada ver-tocar- percibir, la tensión muscular al caminar o en posturas determinadas (Cinestesia y dibujo). Dibujar en torno, dibujar alrededor. Dibujar dentro/dibujar fuera (Objeto, espacio, dibujo). Cambiar la escala respecto del formato (Zoom in/zoom out). Atender a los procedimientos de producción para el dibujo con relación al encaje de la imagen en el formato, cuestionando la orientación, ejecución, producción y lectura de la imagen/texto (Procedimiento y formato). Configurar desde la parte al todo y no desde el todo a la parte (Cuestionar esquemas). Dibujar con desplazamiento en torno al objeto, determinando momentos de interés, superponiendo el acto de dibujar a una secuencia o narrativa (Dibujo y duración). Usar de forma inhabitual o no tradicional medios y soportes (Cuestionar funcionalidad de los medios (Sennet, 2009)). Intencionar la marca, línea, punto, segmento o mancha en la representación 
(Disociar o alterar códigos y traducciones gráficas). Basar la acción del dibujo en la kinesis corporal. Atender a la acción de dibujar en relación con la dinámica de la temporalidad (Dibujo, circunstancia y narración). Dibujar consciente de las acciones que se realizan y los efectos que producen para luego escribir sobre la experiencia. Dibujar a partir de la descripción de la acción ("Receta" para dibujar). Incorporar tecnologías y posibilidades de edición en el proceso del dibujo (De lo digital a lo analógico y de lo analógico a lo digital). Atender a las motivaciones personales (Valoraciones para dibujar). Potenciar la intencionalidad en el medio y en el soporte, en la producción, la acción y la reacción (Dibujar sin imagen). Experimentar con modelos perspectivos $y / o$ proyectivos para dibujar (Perspectiva, interpretación, alteración). Estudiar e interpretar la traducción gráfica, el medio de expresión y la motivación respecto de obras de otros dibujantes (Referente e interpretación). Dibujar versus construir (Construcción de modelos para dibujar/dibujar para construir modelos).

Consideramos todos estos posibles escenarios como constituyentes de la consciencia que requiere el desarrollo, develamiento y expresión de la duración (Bachelard, 1978) comprometidas en el verbo dibujar. De este modo y con base en el Listado de Verbos de Richard Serra (Layuno, 2001) originalmente planteados como acciones en torno a la escultura, se puede proponer una serie de acciones con o sin medios y soportes, destinadas a recontextualizar el proceso del dibujo y su resultado: 


\begin{tabular}{|c|c|c|c|}
\hline $\begin{array}{l}\text { Acciones } \\
\text { concretas (Serra), } \\
\text { seleccionadas por } \\
\text { el autor con } \\
\text { relación al dibujo }\end{array}$ & $\begin{array}{l}\text { Acciones } \\
\text { concretas } \\
\text { (León) }\end{array}$ & $\begin{array}{l}\text { Procedimientos (Serra), } \\
\text { seleccionados por el autor } \\
\text { con relación al dibujo }\end{array}$ & Procedimientos (León) \\
\hline $\begin{array}{l}\text { Manchar } \\
\text { Vetear } \\
\text { Salpicar } \\
\text { Recortar } \\
\text { Rasgar } \\
\text { Verter } \\
\text { Esconder } \\
\text { Tejer } \\
\text { Laminar } \\
\text { Borrar } \\
\text { Adherir } \\
\text { Apilar } \\
\text { Diseminar } \\
\text { Marcar } \\
\text { Reparar } \\
\text { Emparejar }\end{array}$ & $\begin{array}{l}\text { Caminar } \\
\text { Borrar } \\
\text { Apuntar } \\
\text { Palpar } \\
\text { Calcar } \\
\text { Raspar } \\
\text { Trazar } \\
\text { Medir } \\
\text { Sombrear }\end{array}$ & 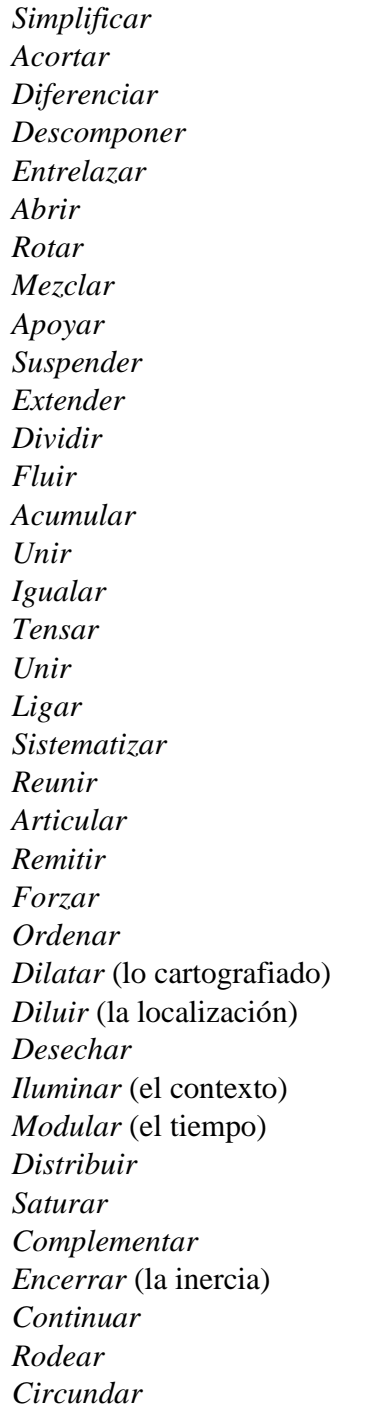 & $\begin{array}{l}\text { Yuxtaponer } \\
\text { Superponer } \\
\text { Iluminar } \\
\text { Consignar } \\
\text { Delimitar } \\
\text { Componer } \\
\text { Descomponer } \\
\text { Fragmentar } \\
\text { Detallar } \\
\text { Reflejar } \\
\text { Proporcionar } \\
\text { Desproporcionar } \\
\text { Contrastar } \\
\text { Segmentar } \\
\text { Contraer } \\
\text { Expandir } \\
\text { Excluir } \\
\text { Incluir } \\
\text { Ritualizar }\end{array}$ \\
\hline
\end{tabular}


El sentido de la acción y sus combinaciones dependería de la posibilidad para redefinir y, de ese modo, renovar los límites del dibujo, incluso bajo un criterio distinto del expuesto. Por ejemplo, en el caso de vincular opuestos tales como Incluir vs Excluir.

Conscientes de que lo señalado no agota los alcances que las cuestiones funcionales y procedimentales surgen en el acontecimiento del dibujar, presentaremos un ejercicio que pone en tensión el nexo entre la imagen dibujada con la o las posiciones que toma el dibujante respecto de un formato. Esto, en referencia a la consideración de los puntos cardinales al registrar in situ, asunto expuesto en mi tesis doctoral (León, 2019), donde se aborda la diferencia conceptual y práctica entre la experiencia de dibujar a vs dibujar en, para plantear posibles respuestas al problema de qué se pregunta el dibujante ante la escena y de qué forma lo traduce y comunica.

\section{Coreografía/Cartografía, un Caso de Acontecimientos no Programables en la Acción de Dibujar.}

En dicha oportunidad, el objetivo del ejercicio consistía en registrar un recorrido que denominamos Paseo de un domingo por la tarde en la ciudad de Barcelona (León, 2019), y la cuestión comenzó cuando sentimos necesario relacionar los puntos cardinales con la orientación requerida para registrar un determinado momento del motivo, toda vez que reconocimos cierta objetividad de comunicación gráfica en ese sistema de referencia cartesiano en un formato plano, ante la experiencia del paisaje que nos rodeaba. Entonces nos preguntábamos: ¿Qué otras formas de representación podríamos producir y cómo afectarían a la comunicación y reconocimiento de los lugares que se fueron develando en el recorrido? Ello porque hasta ese momento y durante el registro in situ, las referencias de ubicación tenían que ver con el cuerpo que percibe y ciertos hitos del entorno, es decir, con posiciones relativas como "pendiente arriba, hacia la izquierda" y similares.

Así, respecto de la convención en la que el norte se representa en formato plano con una flecha hacia arriba, habitual en mapas y planos, nos preguntábamos acerca de traducciones gráficas posibles para las posiciones que demanda lo que está ahí (Gombrich, 1998) con relación al espacio de representación gráfico bidimensional. En otras palabras, nos preguntábamos sobre la coreografía que el dibujante desarrolla in situ respecto del motivo. ¿Cuáles podrían ser las referencias subjetivas para que opere su reconocimiento y comunicación, de forma tal que, a nivel de orientación espacial, una experiencia sobre un entorno se pueda comunicar y compartir 
mediante códigos gráficos dibujados? ¿Hasta dónde es posible comunicar y orientarnos respecto de una imagen dibujada o cómo nos interpela para evidenciar aquello? ¿Por qué el dibujante mostró la imagen en ese formato y con qué referencias físicas, sensoriales, personales y de qué forma el receptor logra aprehender esa experiencia en el dibujo? ¿Qué tipo de operación(es) hace el espectador frente a un registro para reconocer y reconocerse en términos espaciales? Planteado así, dibujar es una experiencia en el espacio, tanto como lo es la contemplación del dibujo.

Con estas preguntas nos propusimos un pie forzado para producir cierta cartografía que recogiera la experiencia coreográfica del recorrido parcialmente registrado, y que para efectos de este artículo presentamos junto con las imágenes 3 a 8, 11 a 16, 18 a 22 y 24 a 27, asociadas directamente con los sectores comprendidos en las cartografías, en las que se consideró la orientación espacial de lo que está ahí respecto de traducciones gráficas relativas a la convención aludida, experiencia que aquí denominaremos cartografías coreográficas y que corresponden a las imágenes 2, 9, 10, 17 y 23.

Al tratarse de una coreografía cartográfica producida in situ, sin más guía objetiva que la brújula de nuestro celular, se decidió que las dimensiones para estos registros no se ceñirían a una medida o proporción específica, sino que serían consecuencia de la orientación en el formato producto de las traducciones gráficas en planta y dibujos asociados a las representaciones de entornos o lugares. Es importante señalar que tanto las planimetrías diagramáticas como los registros y apuntes gráficos de estas cartografías se produjeron en terreno, y que ya contábamos con una experiencia de registro sobre este recorrido. Por ello, dichas cartografías son el resultado de un recorrido coreográfico ya realizado, pero del cual no teníamos total consciencia respecto de sus orientaciones específicas ni las imágenes a lograr. El ejercicio se concibió como Coreografía que deviene en Cartografía y Cartografía que deviene en Coreografía..., para arribar a la evidencia gráfica de las diversas orientaciones que demandaba nuestra elección de locaciones conforme se desarrollaba ese recorrido. 


\section{Momentos del Proceso}

Para las cartografías, nuestro pie forzado consistió en ubicar el norte hacia arriba en formato lámina de dimensiones $70 \times 100 \mathrm{~cm}$. Activada la aplicación Brújula, fijamos el celular con cinta adhesiva sobre un soporte de terciado de $30 \times 37 \mathrm{~cm}$ y $3 \mathrm{~mm}$ de espesor, utilizado como apoyo para las láminas de papel sobre las que se realizaba el registro cartográfico. Una vez desplegado el formato, realizamos la cartografía mediante movimientos de lámina, teniendo por referencia el Norte de la brújula (como ilustra la Imagen 1 sobre un ejemplo en formato libreta para orientar el registro según nuestra posición como observadores de lo que está ahî). Es decir, conforme nuestro cuerpo enfrentaba el paisaje circundante respecto de una orientación indicada en la brújula, movíamos y situábamos el formato asemejando la orientación respecto del Norte consignado previamente en la lámina, siguiendo la convención en donde dicho punto cardinal se indica con una flecha hacia arriba.

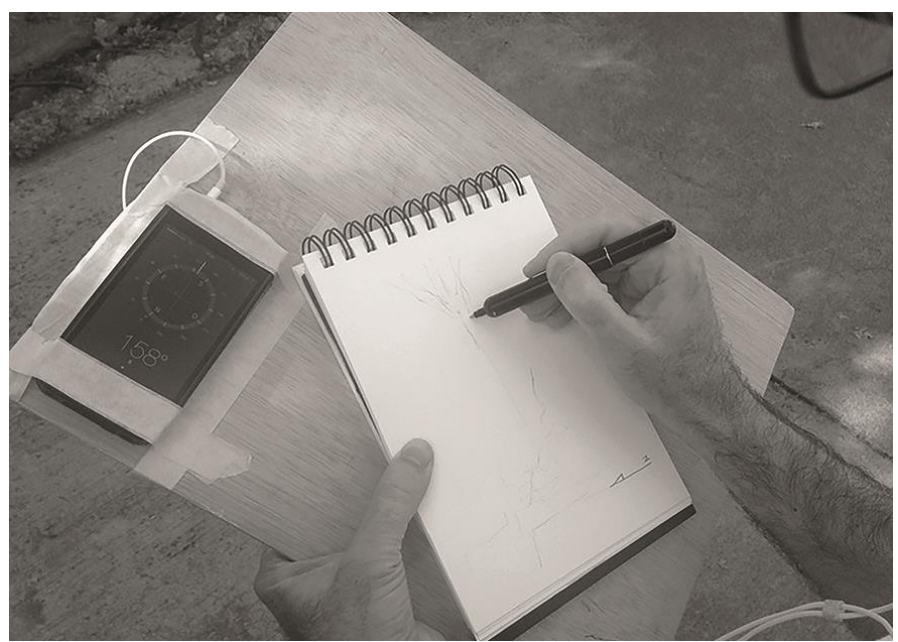

Imagen 1. Panussis, H (2018). Ejemplo de dibujo orientado sobre libreta, en donde el autor utiliza soporte de madera como apoyo para dibujar y fijar la aplicación Brújula del iPhone 4. Santiago, Chile.

Para el procedimiento de cartografía coreográfica al que hacemos alusión, ¿cuál sería su posición para ser expuesto? ¿Sobre un muro que permita "leer" en posición vertical o en una superficie horizontal a determinada altura para ser perimetral y coreográficamente comprendido? 
La cartografía mediante registro en planta de los trazados gráficos para calles, edificaciones y sectores del paisaje en general, así como los croquis de vistas orientados de acuerdo a como se ha señalado, pusieron a prueba el ejercicio de dibujar en formato rectangular, en donde los límites vertical y horizontal constituyen una referencia y analogía tanto de posición como de orientación espacial, cuestionando referencialmente la convención "Norte hacia arriba" para poner en valor la orientación corporal. De hecho, la relación para un "delante, atrás" o "al lado", una vez trasladada al formato bidimensional orientado referencialmente, transforma la verticalidad y la horizontalidad del formato en un espacio de representación que se puede rodear y que no tiene posición fija, lo cual requiere moverse en torno al formato sobre un plano horizontal, es decir, reconstruir a escala relativa una coreografía de movimientos respecto a ciertas zonas notables puestas en valor y traducidas gráficamente.

En función de registrar cuestiones orientativas, se podría consignar la fecha, hora, posición e incidencia del sol mediante la expresión valorativa de luz-sombra, si las condiciones climáticas lo permiten. También es posible consignar en lámina la dirección que indique la brújula respecto de la posición del dibujante ante el motivo, pero manteniendo las referencias verticales y horizontales del formato, para así reconocer y reconstruir la información relacionada con la orientación que exponen las imágenes y su luz-sombra. Es decir, se podrían reconstruir las posiciones desde las cuales se ha registrado, relacionando los datos visuales y escritos como decodificación que documenta aspectos como una circunstancia, posiciones y luz ambiental. En dicho caso los datos, cuyo valor es objetivo y radica en aspectos racionales descifrables, no necesariamente involucrarían en su dimensión corporal (subjetiva o del individuo) a quien se interese por decodificarlos. De ahí que consideremos este acontecimiento cartográfico/coreográfico como un registro de movimientos corporales que vinculan a dibujante, imagen y espectador, a diferencia de la constatación mental de datos objetivos que requieren ser descifrados.

Esta experiencia llevó a reflexionar críticamente sobre la funcionalidad de ciertos formatos. Al momento de levantar información gráfica de un recorrido mediante dibujo en planta, complementado con notaciones y vistas hechas a mano alzada, cuyas características interpelan al dibujante y que valoraríamos psicológicamente mediante la acción del dibujo, se cuestiona la convencionalidad del formato rectangular como medio de comunicación apropiado a los desplazamientos necesarios y las posiciones elegidas que, necesariamente, resultan de los movimientos corporales que el dibujante 
efectúa a modo de coreografía, respecto de las características y cualidades que le ofrece el lugar. Esta reflexión ocurre durante el proceso del dibujo no siendo posible de anticipar como etapa de un proyecto artístico, al menos bajo la forma en que actualmente se miden sus parámetros de factibilidad, aunque nada impide que ello se acoja si los criterios de recepción y evaluación para dichos proyectos, se replantean en sintonía con lo propio de la creación en su constante descubrimiento.

En este punto, es necesario insistir en la necesidad de hacernos preguntas correctamente orientadas hacia nuestro hacer /pensar práctico y no endosar el papel principal al oficio, determinada técnica o ajuste metodológico. Es necesario evitar el desvío en formalidades que puedan oscurecer los alcances y posibilidades que surgirán del acontecimiento del dibujar. Así, pondremos el énfasis en las preguntas derivadas de la práctica y que a su vez la nutren, en lugar de concentrar todas las energías en el resultado o su "productividad". Como ya se ha señalado, los parámetros de evaluación de proyectos artísticos constituyen materia de debate incluso en la Academia y al respecto, si la parametrización es inevitable, nada impide que ésta se abra a una reformulación que acoja la naturaleza no predecible del acontecimiento en la creación, como se plantea en el ejemplo que presentamos.

\section{El Acontecimiento en una Experiencia de Dibujo}

Para contextualizar las Cartografías Coreográficas y la naturaleza de su acontecer, se han seleccionado una serie de láminas con registros que abarcan los sectores relativos al recorrido Paseo de un domingo por la tarde (León, 2019) en imágenes 3 a 8, 11 a 16, 18 a 22 y 24 a 27. Dado que estos registros se realizaron con el objetivo de reconstruir la memoria de un paseo al azar realizado en marzo de 2016, durante cuya evolución no fuimos particularmente conscientes de las posiciones u orientaciones espaciales que elegíamos para registrar y que comenzábamos a cuestionar, consideramos interesante relacionar los registros más detallados de las láminas seleccionadas con las plantas esquemáticas, vistas y datos contenidos en las Cartografías Coreográficas. Esta proposición no derivó de una producción gráfica planificada, sino de la constatación posterior de recurrencias observables que se complementan, posibilitando la articulación y comprensión del espacio registrado respecto de las orientaciones elegidas. 


\section{Cartografía Coreográfica 01 (Lámina 114) Asociada a Selección de Registros en Láminas para el Correspondiente Tramo del Recorrido} Paseo de un domingo por la tarde.

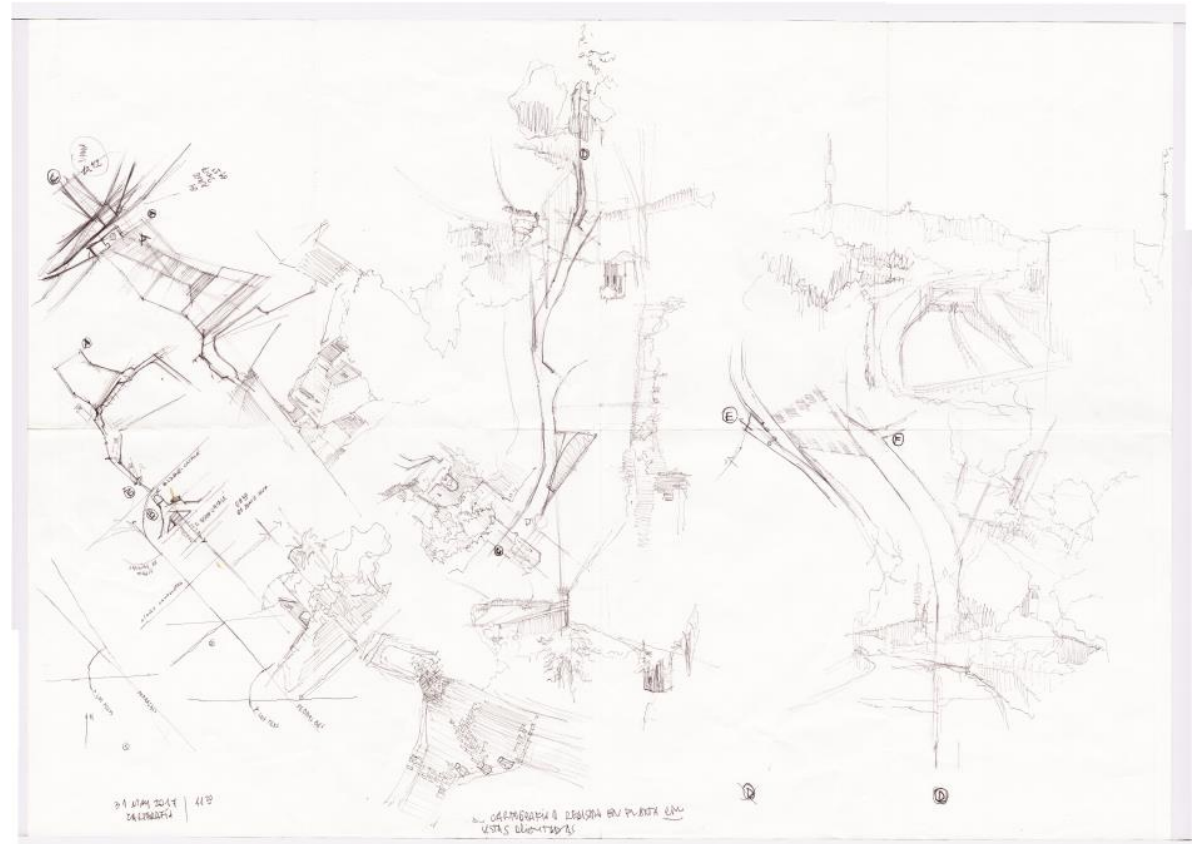

Imagen 2. León Luque, José Ignacio (2017). CARTOGRAFÍA COREOGRÁFICA 01 (Lámina 114). Cartografía y registro orientado de traducciones gráficas para vistas en planta y croquis en el recorrido Paseo de un domingo por la tarde que comprende Residencia Universitaria Resa Torre Girona - Baixada del Monestir-Carrer de Gaspar Cassadó-Acceso a Parc de l'Oreneta. Bolígrafo negro sobre papel Torreón $70 \times 100$ $\mathrm{cm}, 120 \mathrm{gr}$, plegado por el autor. 


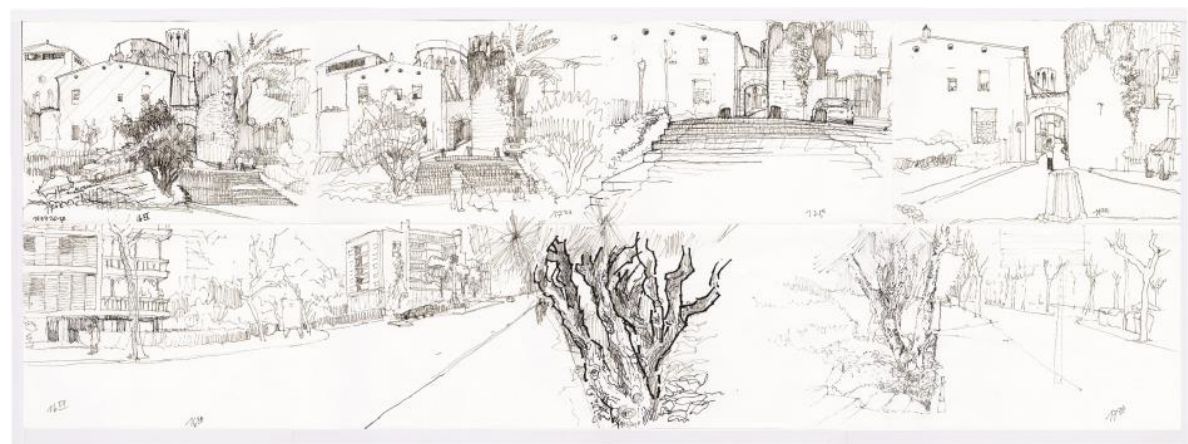

Imagen 3. León Luque, José Ignacio (2017). Lámina 47. Registros para el sector comprendido por Av. d'Esplugues, Baixada del Monestir, Reial Monestir de Santa Maria de Pedralbes y Carrer del Bisbe Catalá. Téc. Mixta: pluma, rotulador, rotulador punta pincel sobre papel Torreón $35 \times 100 \mathrm{~cm}, 120 \mathrm{gr}$, plegado por el autor.

El tercer registro de la fila superior, junto con el primero y segundo de la fila inferior, corresponden a una misma posición de observación y tres puntos de vista diferentes.

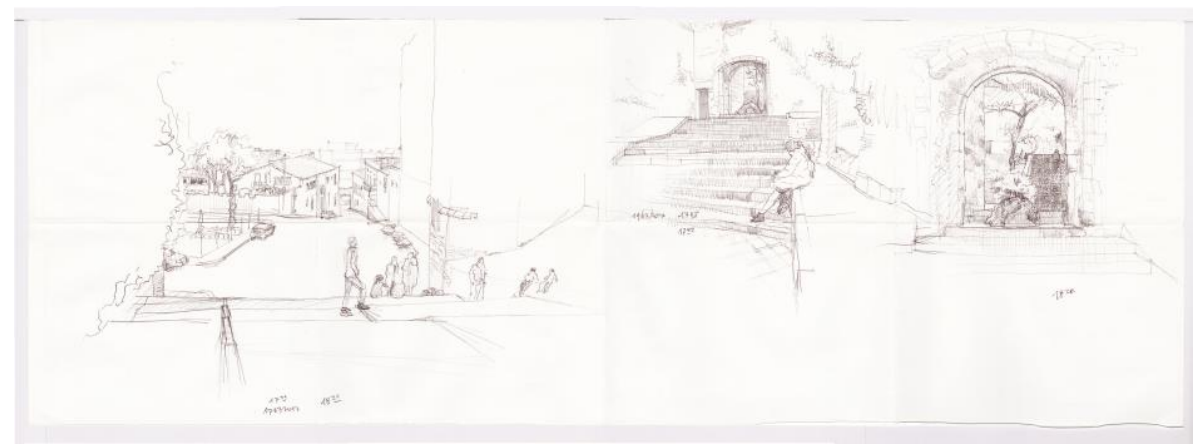

Imagen 4. León Luque, José Ignacio (2017). Lámina 53. Registros para el sector comprendido por Baixada del Monestir y Plaça del Monestir. Bolígrafo negro sobre papel Torreón $35 \times 100 \mathrm{~cm}, 120 \mathrm{gr}$, plegado por el autor. 


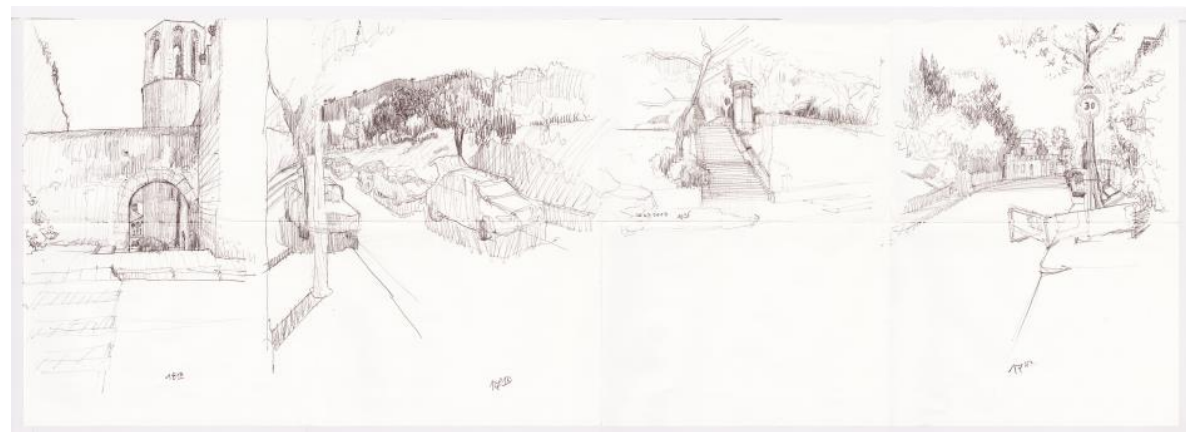

Imagen 5. León Luque, José Ignacio (2017). Lámina 54. Registros para el sector comprendido por Carrer de Montevideo con Baixada del Monestir. Bolígrafo negro sobre papel Torreón $35 \times 100 \mathrm{~cm}, 120$ gr, plegado por el autor.

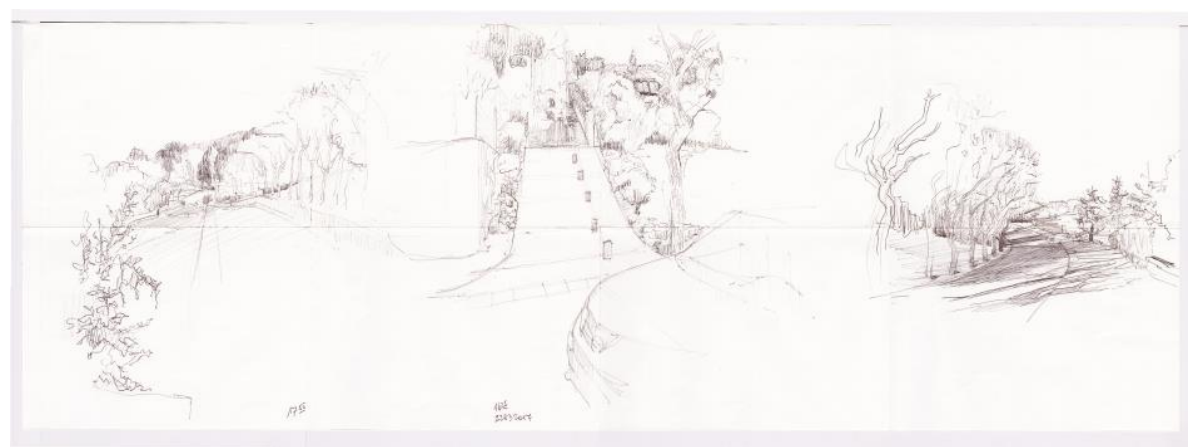

Imagen 6. León Luque, José Ignacio (2017). Lámina 55. Registros para el sector comprendido por Carrer de Gaspar Cassadó, C. de Joan Orpí y Parc de l'Oreneta. Bolígrafo negro sobre papel Torreón $35 \times 100 \mathrm{~cm}, 120 \mathrm{gr}$, plegado por el autor. 


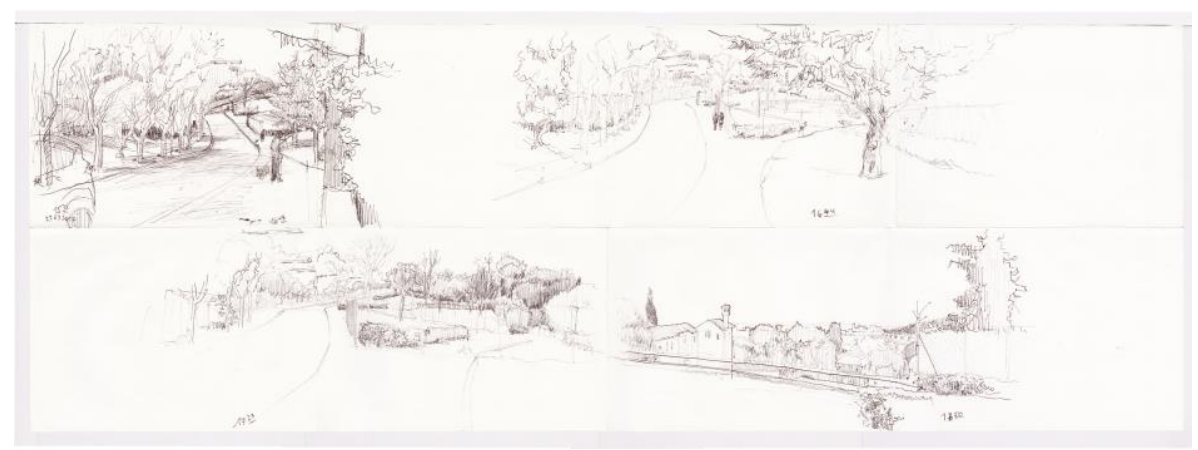

Imagen 7. León Luque, José Ignacio (2017). Lámina 57. Registros para el sector comprendido por Carrer de Gaspar Cassadó y Parc de l'Oreneta. Bolígrafo negro sobre papel Torreón $35 \times 100 \mathrm{~cm}, 120 \mathrm{gr}$, plegado por el autor.

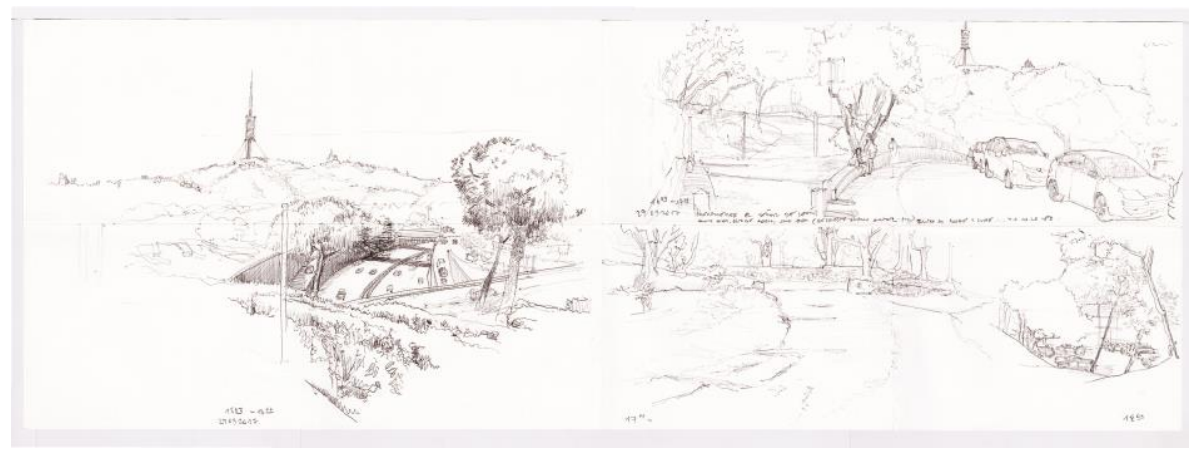

Imagen 8. León Luque, José Ignacio (2017). Lámina 63. Registros para el sector comprendido por Carrer de Gaspar Cassadó, Ronda de Dalt \& B20 y Parc de l'Oreneta. Bolígrafo negro sobre papel Guarro $35 \times 100 \mathrm{~cm}, 150 \mathrm{gr}$, plegado por el autor. 
Cartografía Coreográfica 02 y 03 (Láminas 117 y 118) Asociada a Selección de Registros en Láminas para el Correspondiente Tramo del Recorrido Paseo de un Domingo por la Tarde

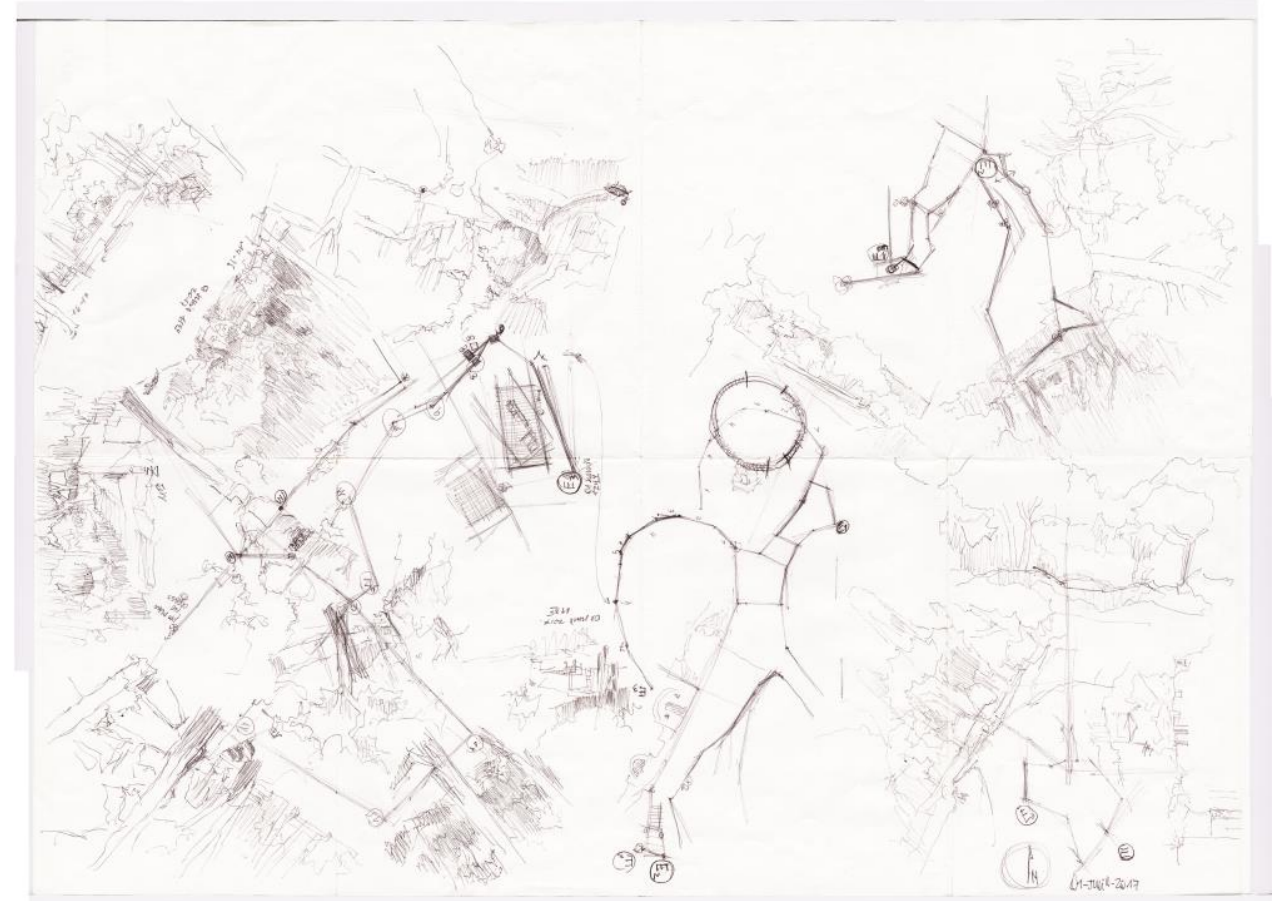

Imagen 9. León Luque, José Ignacio (2017). Cartografía coreográfica 02 (Lámina 117). Cartografía y registro orientado de traducciones gráficas para vistas en planta y croquis del recorrido Paseo de un domingo por la tarde que comprende Parc del Castel de l'Oreneta. Bolígrafo negro sobre papel Torreón $70 \times 100 \mathrm{~cm}, 120$ gr, plegado por el autor. 


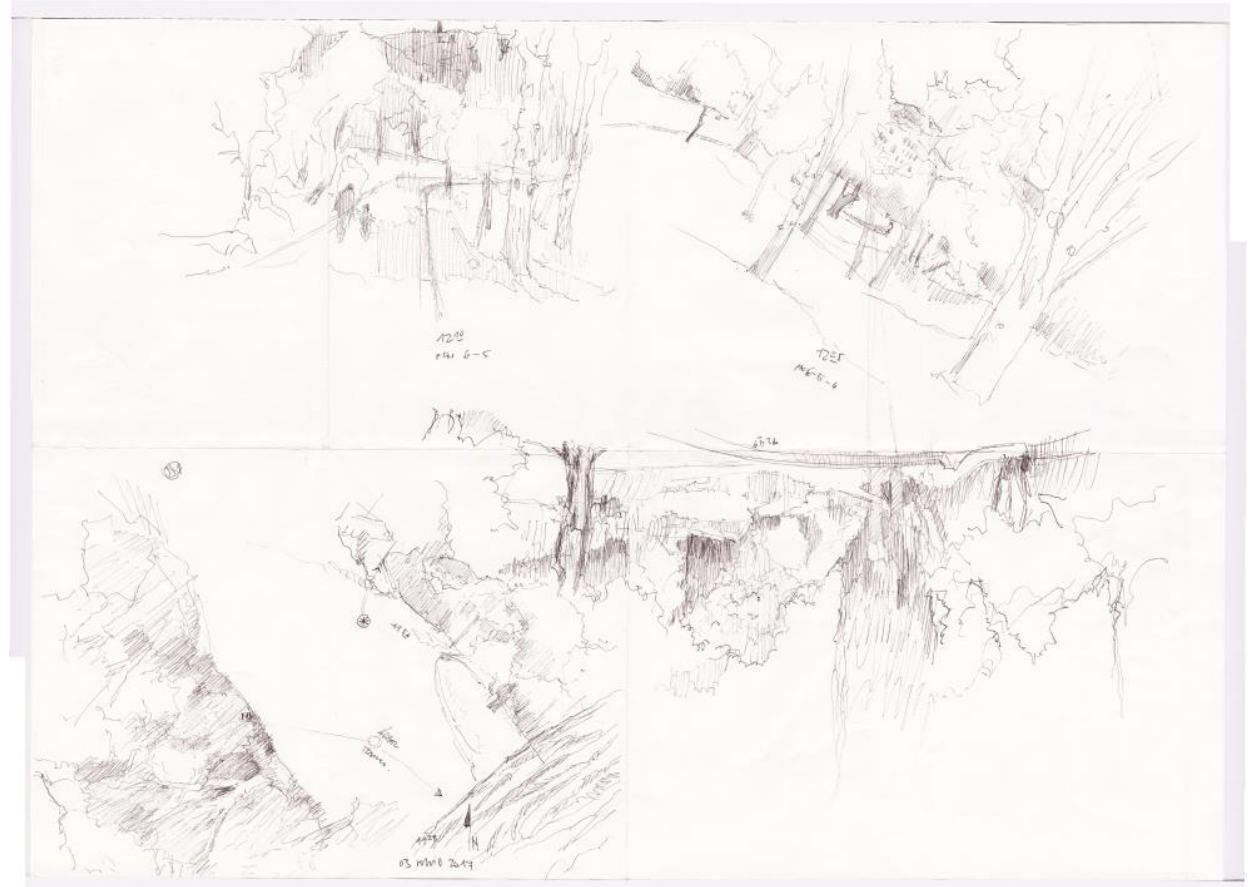

Imagen 10. León Luque, José Ignacio (2017). Cartografía coreográfica 03 (Lámina 118). Cartografía y registro orientado de traducciones gráficas para vistas en planta y croquis del recorrido Paseo de un domingo por la tarde que comprende Parc del Castel de l'Oreneta. Bolígrafo negro sobre papel Torreón $70 \times 100 \mathrm{~cm}, 120 \mathrm{gr}$, plegado por el autor. 


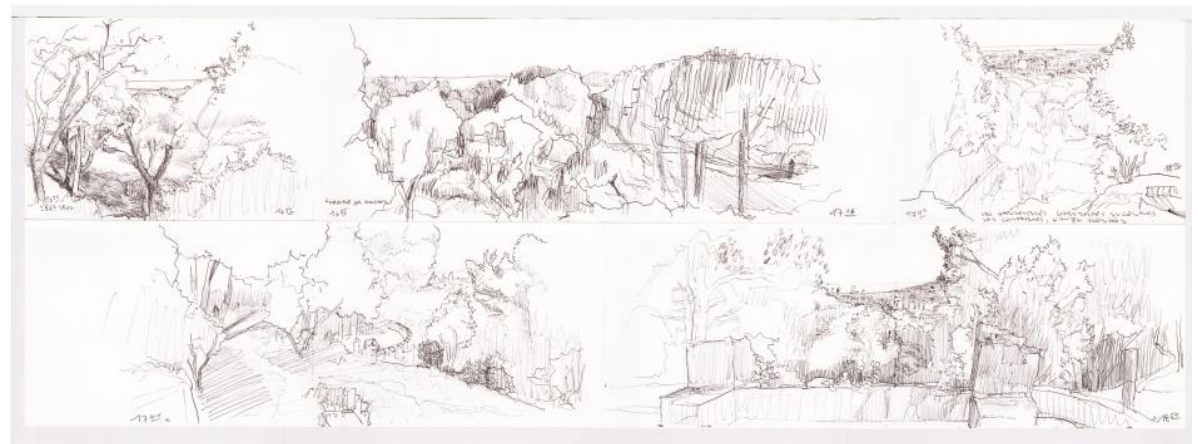

Imagen 11. León Luque, José Ignacio (2017). Lámina 62. Registros para un sector en Parc del Castel de l'Oreneta. Bolígrafo negro sobre papel Guarro Dibujo Basik $35 \times$ $100 \mathrm{~cm}, 150 \mathrm{gr}$, plegado por el autor.

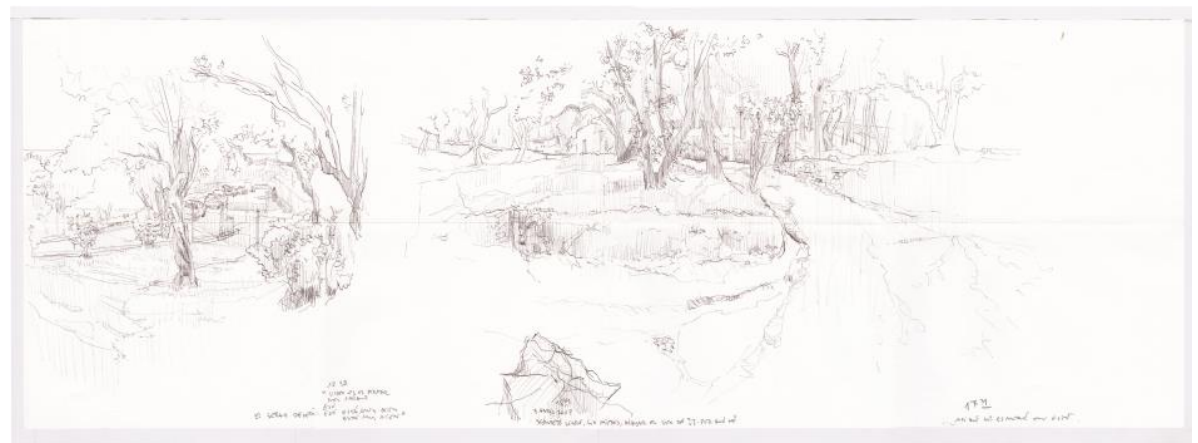

Imagen 12. León Luque, José Ignacio (2017). Lámina 67. Registros para un sector en Parc del Castel de l'Oreneta. Bolígrafo negro sobre papel Guarro Dibujo Basik $35 \times$ $100, \mathrm{~cm} 150 \mathrm{gr}$, plegado por el autor. 


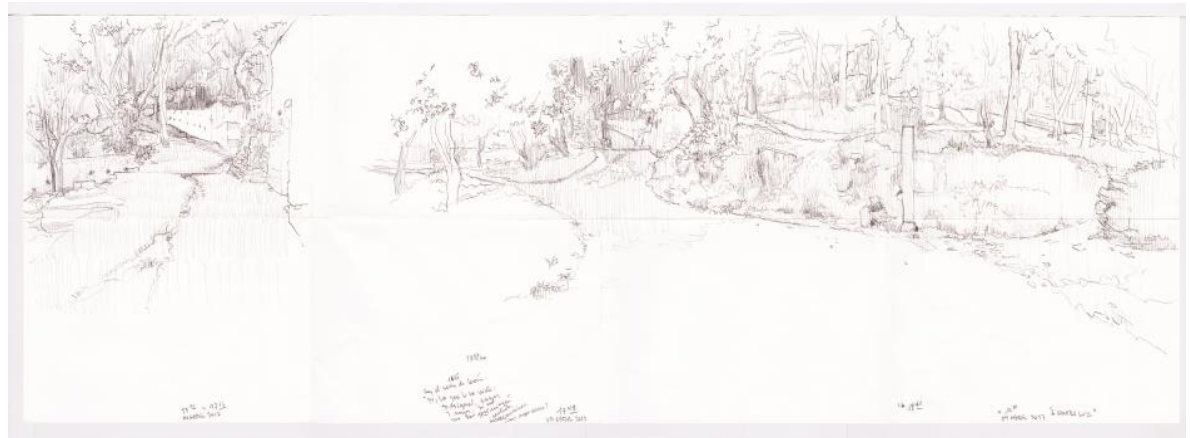

Imagen 13. León Luque, José Ignacio (2017). Lámina 68. Registros para un sector en Parc del Castel de l'Oreneta. Bolígrafo negro sobre papel Guarro Dibujo Basik $35 \times 100 \mathrm{~cm}, 150 \mathrm{gr}$, plegado por el autor.

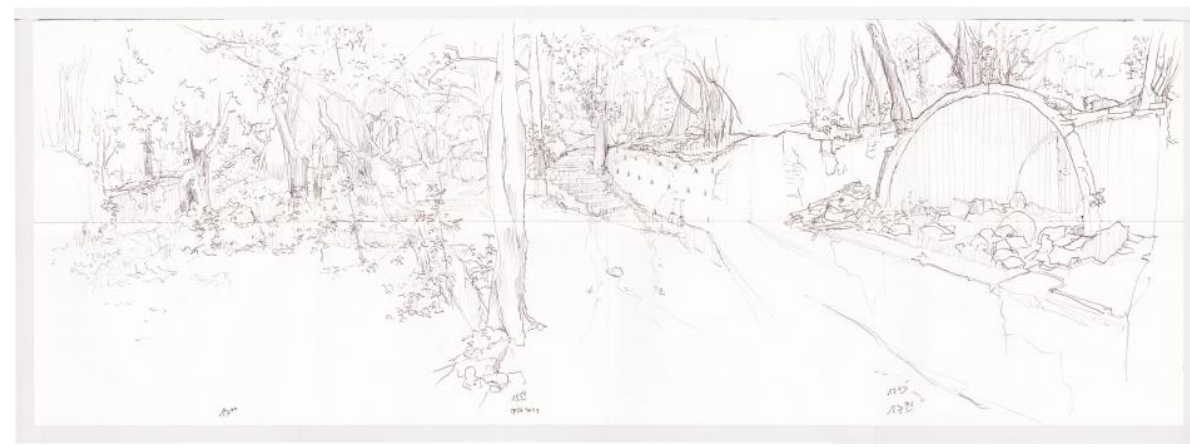

Imagen 14. León Luque, José Ignacio (2017). Lámina 71. Registros para un sector en Parc del Castel de l'Oreneta. Bolígrafo negro sobre papel Guarro Dibujo Basik $35 \times$ $100 \mathrm{~cm}, 150 \mathrm{gr}$, plegado por el autor. 


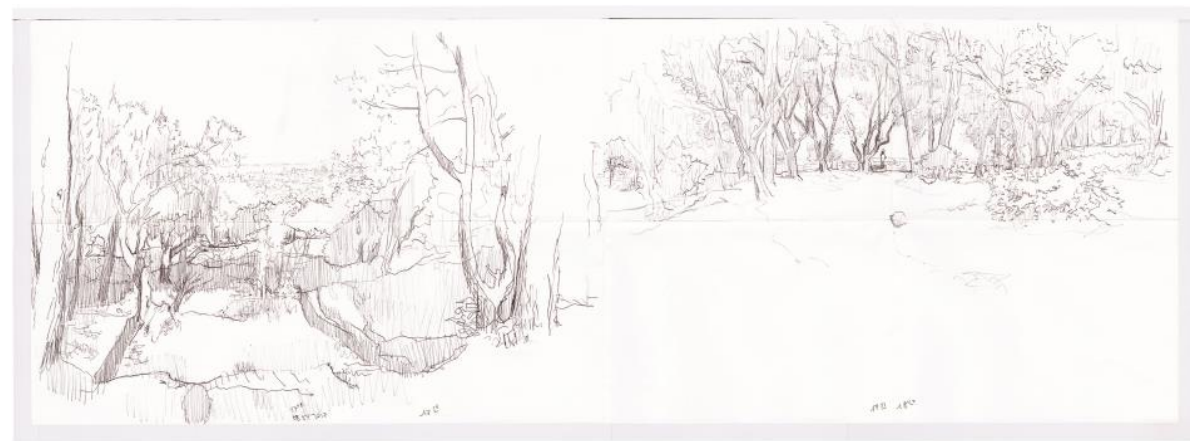

Imagen 15. León Luque, José Ignacio (2017). Lámina 73. Registros para un sector en Parc del Castel de l'Oreneta. Bolígrafo negro sobre papel Guarro Dibujo Basik $35 \times$ $100 \mathrm{~cm}, 150 \mathrm{gr}$, plegado por el autor.

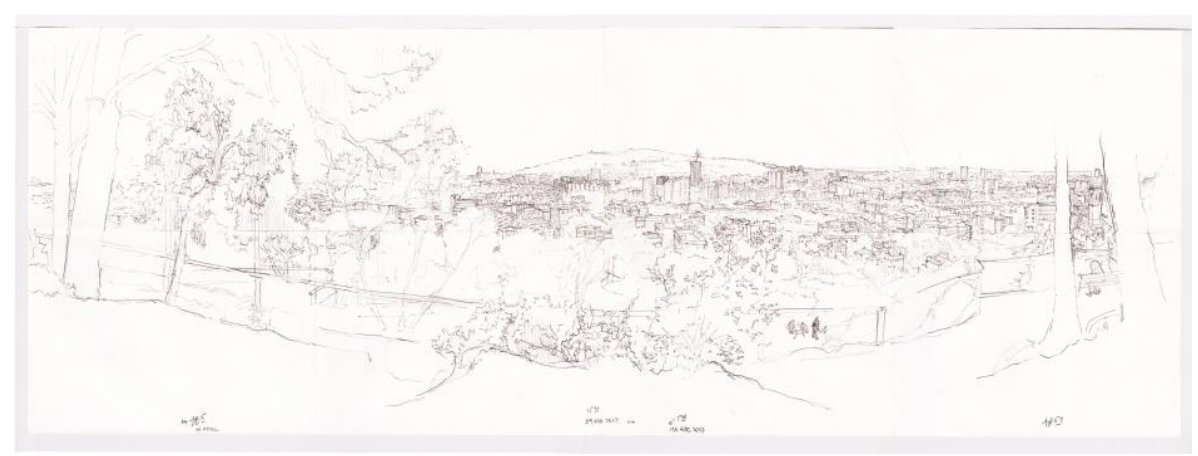

Imagen 16. León Luque, José Ignacio (2017). Lámina 74. Registros para mirador en Parc del Castel de l'Oreneta. Bolígrafo negro sobre papel Guarro Dibujo Basik, $35 \times$ $100 \mathrm{~cm}, 150 \mathrm{gr}$, plegado por el autor. 


\section{Cartografía Coreográfica 04 (Lámina 120) Asociada a Selección de Registros en Láminas para el Correspondiente Tramo del Recorrido Paseo de un Domingo por la Tarde}

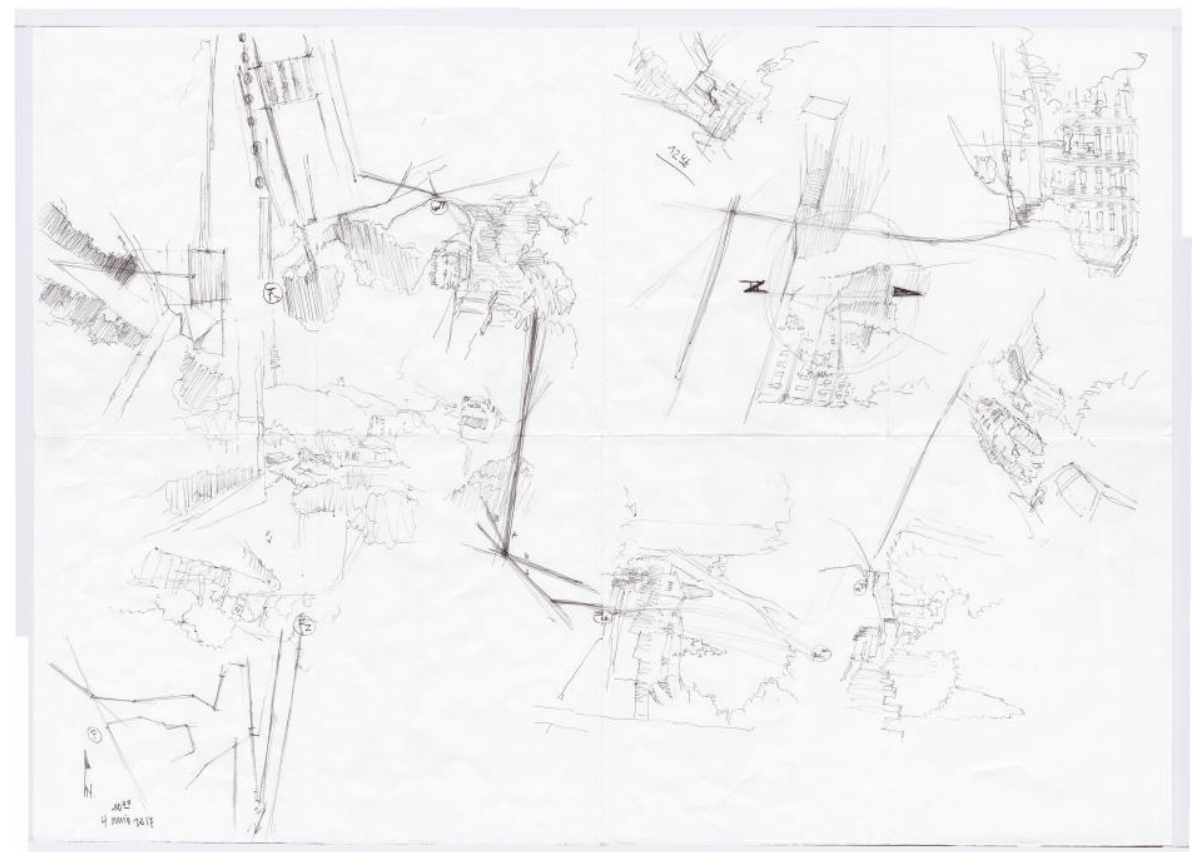

Imagen 17. León Luque, José Ignacio (2017). Cartografía Coreográfica 04 (Lámina 120). Cartografía y registro orientado de traducciones gráficas para vistas en planta y croquis del recorrido Paseo de un domingo por la tarde que comprende Carrer de Gaspar Cassadó, Ronda de Dalt \& B20, Carre d'Elisenda de Pinós, Carrer de Pere II de Montcada, Carrer del Monestir y Carrer de Ramon Miquel i Planas. Bolígrafo negro sobre papel Torreón $70 \times 100 \mathrm{~cm}, 120 \mathrm{gr}$, plegado por el autor. 


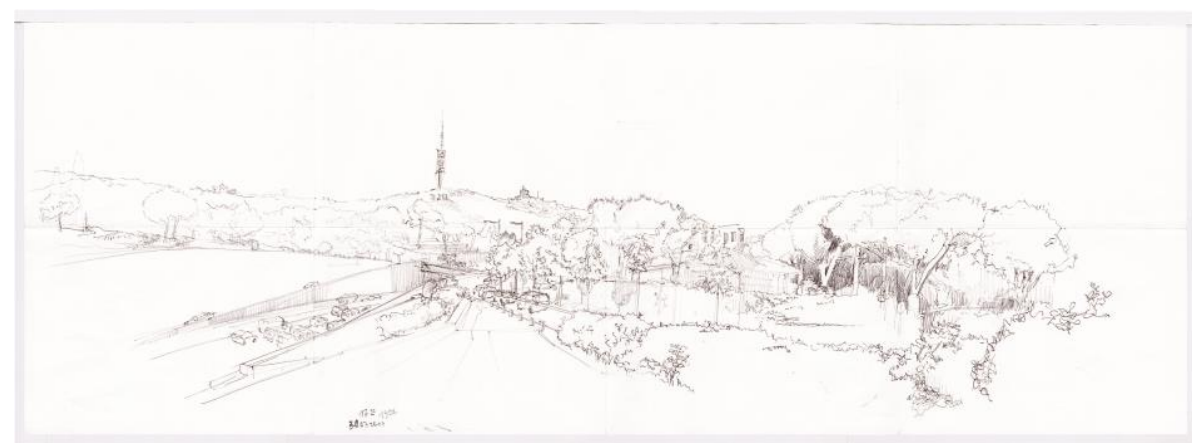

Imagen 18. León Luque, José Ignacio (2017). Lámina 65. Registros para el sector comprendido por Ronda de Dalt \& B20, Carrer de Montevideo y Carrer de Elisenda de Pinós. Bolígrafo negro sobre papel Guarro Dibujo Basik $35 \times 100 \mathrm{~cm}, 150$ gr, plegado por el autor.

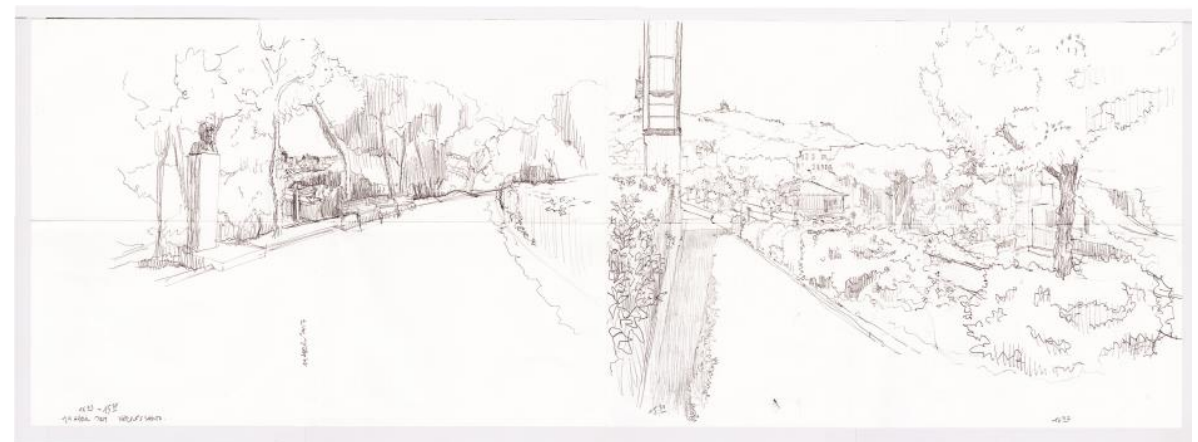

Imagen 19. León Luque, José Ignacio (2017). Lámina 75. Registros para el sector comprendido por Ronda de Dalt \& B20, Carrer de Montevideo y Carrer de Elisenda de Pinós. Bolígrafo negro sobre papel Guarro Dibujo Basik $35 \times 100 \mathrm{~cm}, 150$ gr, plegado por el autor. 


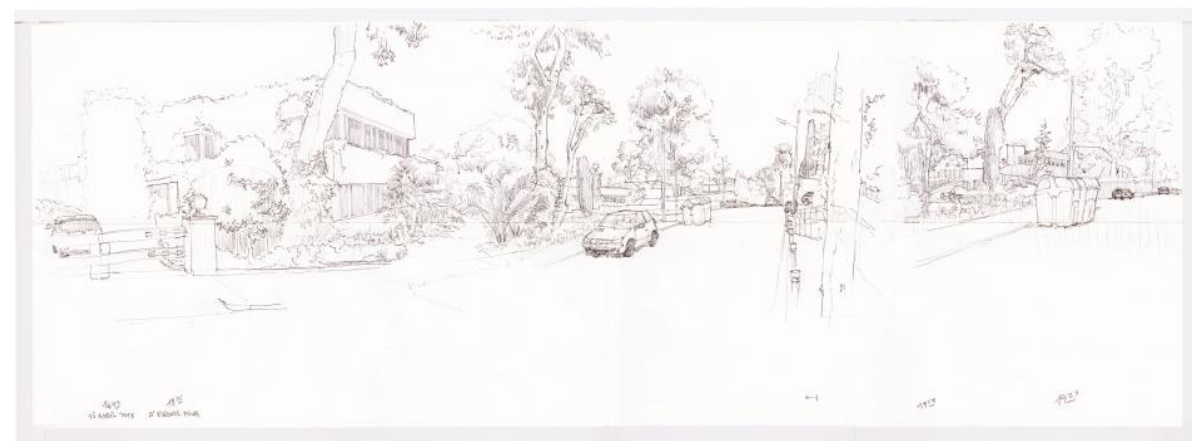

Imagen 20. León Luque, José Ignacio (2017). Lámina 77. Registros para el sector comprendido por Carrer d'Elisenda de Pinós y Carrer de Pere II de Montcada. Bolígrafo color negro sobre papel Guarro Dibujo Basik $35 \times 100 \mathrm{~cm}, 150$ gr, plegado por el autor.

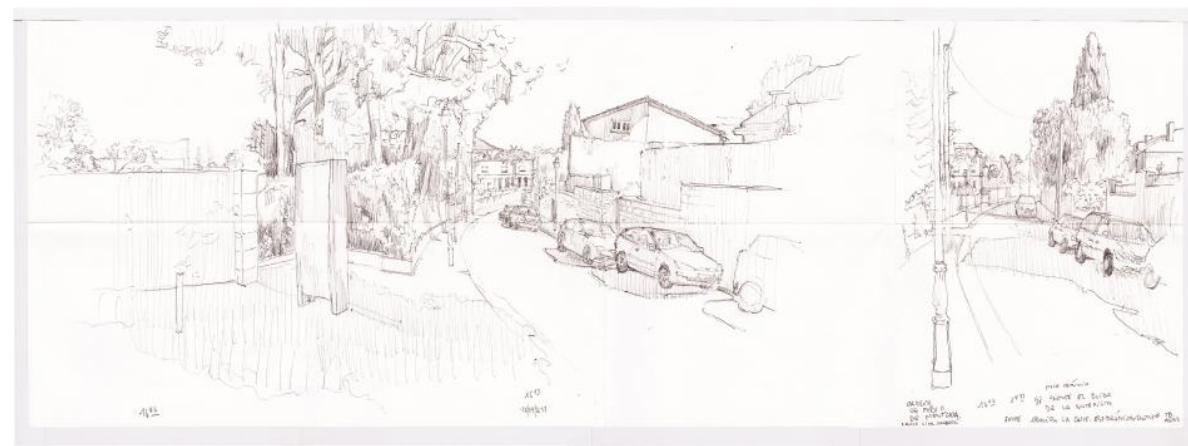

Imagen 21. León Luque, José Ignacio (2017). Lámina 79. Registros para el sector comprendido por Carrer de Pere II de Montcada y Passeig de la Reina Elisenda de Montcada. Bolígrafo negro sobre papel Guarro Dibujo Basik, $35 \times 100 \mathrm{~cm}, 150 \mathrm{gr}$, plegado por el autor. 


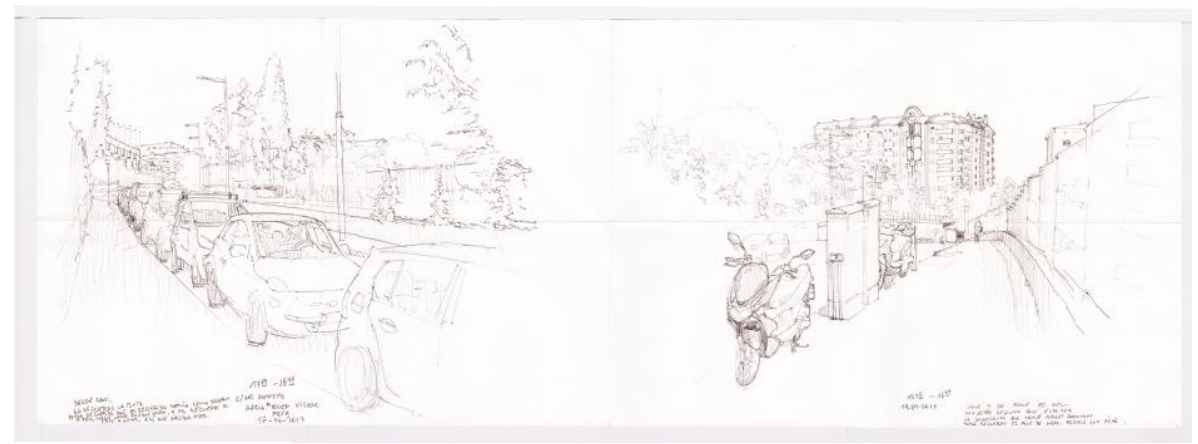

Imagen 22. León Luque, José Ignacio (2017). Lámina 80. Registros para el sector comprendido por Carrer del Monestir y Av. de Josep Vicenç Foix. Bolígrafo negro sobre papel Guarro Dibujo Basik $35 \times 100 \mathrm{~cm}, 150 \mathrm{gr}$, plegado por el autor. 


\section{Cartografía Coreográfica 05 (Lámina 122) Asociada a Selección de Registros en Láminas para el Correspondiente Tramo del Recorrido Paseo de un Domingo por la Tarde}

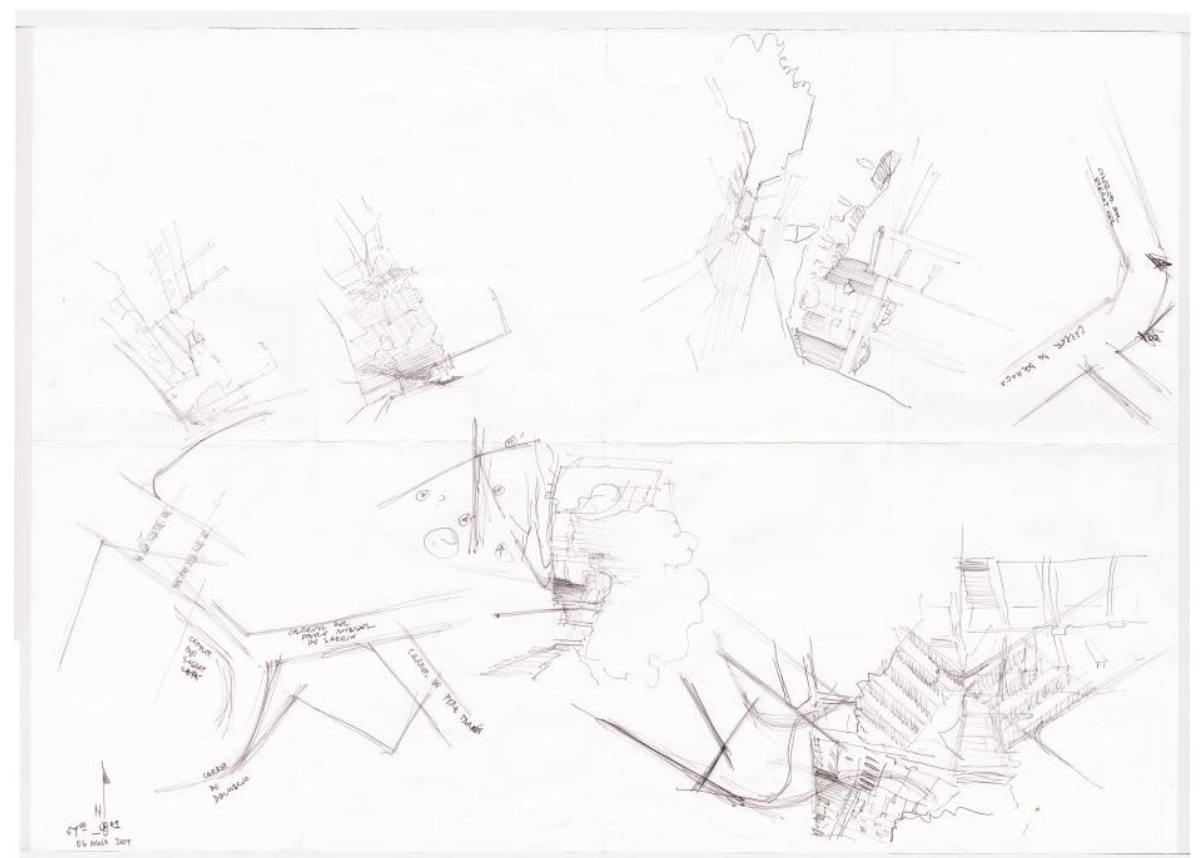

Imagen 23. León Luque, José Ignacio (2017). Cartografía Coreográfica 05 (Lámina 122). Cartografía y registro orientado de traducciones gráficas para vistas en planta y croquis del recorrido Paseo de un domingo por la tarde que comprende Carrer de Ramon Mique i Planas, Carrer de la Duquessa d'Orleans, Carrer de Dalmàcia y Carrer del Pare Miquel de Sarrià. Bolígrafo negro sobre papel Torreón $70 \times 100$ cm, 120 gr, plegado por el autor. 


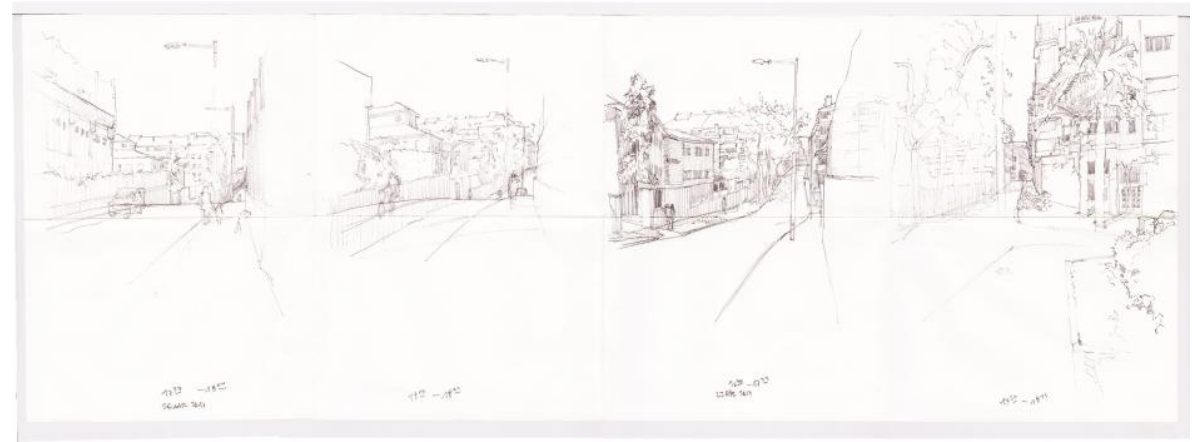

Imagen 24. León Luque, José Ignacio (2017). Lámina 83. Registros para el sector comprendido por Carrer de Ramon Miquel i Planas y Carrer de la Duquessa d'Orleans. Bolígrafo negro sobre papel Guarro Dibujo Basik $35 \times 100 \mathrm{~cm}, 150 \mathrm{gr}$ plegado por el autor.

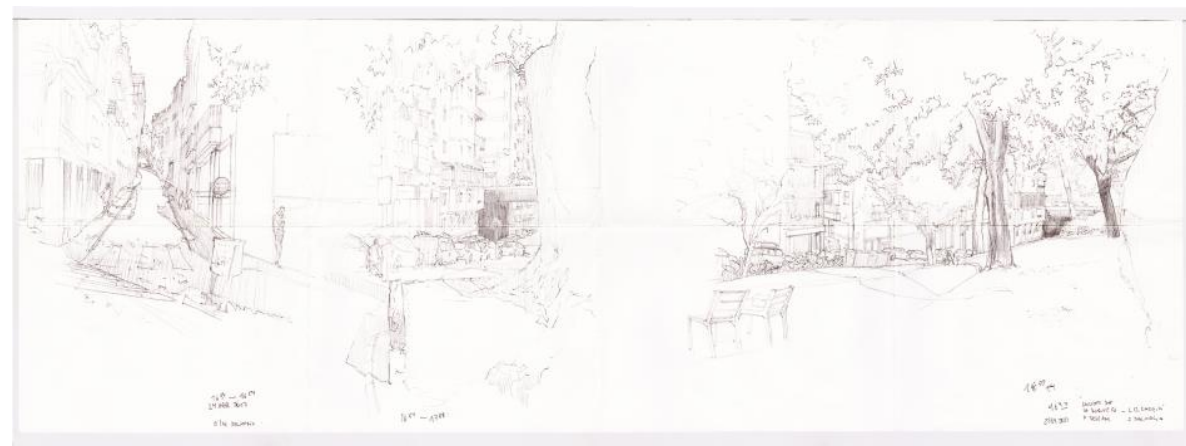

Imagen 25. León Luque, José Ignacio (2017). Lámina 85. Registros para el sector comprendido por Carrer de la Duquessa d'Orleans, Carrer de Dalmàcia y Passeig de la Reina Elisenda de Montcada. Bolígrafo negro sobre papel Guarro Dibujo Basik 35 $\times 100 \mathrm{~cm}, 150$ gr, plegado por el autor. 


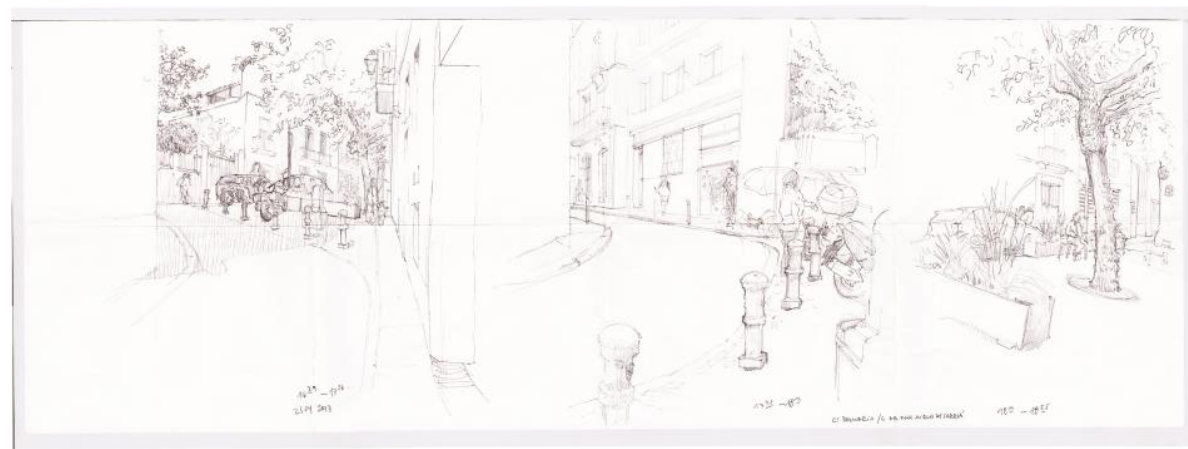

Imagen 26. León Luque, José Ignacio (2017). Lámina 88. Registros para el sector comprendido por Carrer de Dalmàcia Carrer del Pare Miquel de Sarrià - Plaça de Sant Gaietà, Carrer del Sagrat Cor. Bolígrafo negro sobre papel Guarro Dibujo Basik $35 \times$ $100 \mathrm{~cm}, 150$ gr, plegado.

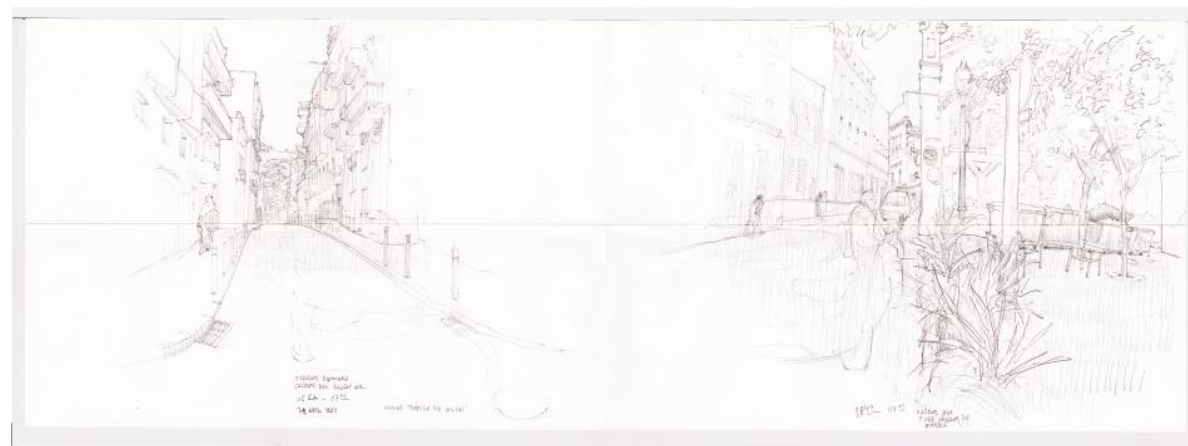

Imagen 27. León Luque, José Ignacio (2017). Lámina 89. Registros para el sector comprendido por Carrer del Sagrat Cor, Carrer del Pare Miquel de Sarrià y Plaça de Sant Gaietà. Bolígrafo negro sobre papel Guarro Dibujo Basik $35 \times 100 \mathrm{~cm}, 150 \mathrm{gr}$, plegado por el autor. 


\section{Conclusión}

Con el presente artículo hemos querido relevar la acción y el suceso por sobre la proyección de actividades necesarias para el desarrollo de un proyecto artístico, de forma tal que se valora el acontecimiento del dibujo en aspectos funcionales y de proceso, lo cual, desde nuestro punto de vista, propicia ampliar sus posibilidades creativas e investigativas y, en consideración a ello, reflexionar sobre los criterios de evaluación. Preguntarnos sobre el dibujo implica tanto al asunto que lo motiva como al medio y formato que surja o se utilice para su expresión, involucrando al dibujante en sus afectos y deseos. Si los procesos, modos y funciones de un dibujo son apremiantes para el autor, la reflexión que acompañará a la práctica y al acontecimiento todo, posibilitarán comprender y comprenderse en el fenómeno. Se trata de un acontecimiento en diversos niveles de ocurrencia y en gran medida impredecible que requiere ser acogido y valorado por quienes participan de una u otra forma en el proceso de la creación.

\section{Referencias}

Bachelard, G. (1978). La Dialéctica de la duración. Villalar.

Borgdorff, H. (2006). El debate sobre la investigación en las artes. Amsterdam School of the Arts.

Dewey, J. (2008). El arte como experiencia. Paidós.

Gombrich, E. H. (1998). Arte e ilusión: estudio sobre la psicología de la representación pictórica. Debate.

Heidegger, M. (1997). La Pregunta por la Técnica en Filosofía, ciencia y técnica. Ed. Universitaria.

Layuno Rosas, M. (2001). Richard Serra. Nerea.

León Luque, José Ignacio. (2019). Recorrido y Conquista. Registros de una Experiencia Extranjera en la Ciudad de Barcelona, 2016-2018 [Tesis doctoral, Universitat De Barcelona]. Dipósit Digital. http://hdl.handle.net/2445/136286

Sennett, R. (2009). El artesano. Anagrama. 
José Ignacio León Luque: Doctor y profesor en la Escuela de Arte. Facultad de Artes de la Pontificia Universidad Católica de Chile. Artista plástico e investigador.

Email address: joseleon@uc.cl

Contact Address: Escuela de Arte. Facultad de Artes Universidad Católica de Chile. Av. Jaime Guzmán Errázuriz 3300. CP 7511261. Santiago. Chile. 